\title{
Ganhos de peso, taxas de deposição e composição química corporal de tourinhos Santa Gertrudes confinados, recebendo alto concentrado e níveis crescentes de polpa cítrica peletizada ${ }^{1}$
}

\author{
Wignez Henrique ${ }^{2}$, Alexandre Amstalden Moraes Sampaio ${ }^{3}$, Paulo Roberto Leme ${ }^{4}$, Dante \\ Pazzanese Duarte Lanna ${ }^{5}$, Guilherme Fernando Alleoni ${ }^{6}$
}

${ }_{1}$ Parte da tese de Doutoramento da primeira autora junto à FCAV/UNESP, Jaboticabal, SP; projeto financiado pela Fapesp

2 APTA/SAA, São José do Rio Preto, SP.

${ }^{3}$ Depto. Zootecnia/FCAV/UNESP, Jaboticabal, SP, Bolsista CNPq.

${ }^{4}$ Depto. Zootecnia/FZEA/USP, Pirassununga, SP, Bolsista CNPq.

${ }^{5}$ Depto. Zootecnia/ESALQ/USP, Piracicaba, SP, Bolsista CNPq.

${ }^{6}$ Instituto de Zootecnia, Nova Odessa, SP.

\begin{abstract}
RESUMO - Objetivou-se avaliar a substituição do milho em grão pela polpa cítrica peletizada e seus efeitos sobre os ganhos de peso, as taxas de deposição e a composição química corporal de tourinhos Santa Gertrudes em confinamento. Vinte e oito animais (idade média de nove meses e peso inicial de $277 \mathrm{~kg}$ ) foram mantidos em baias individuais durante 92 dias, após 21 dias de adaptação. Os animais receberam dietas contendo $20 \%$ da MS como silagem de milho que continha $40 \%$ de grãos. Foram testados os níveis de $0,25,40$ e 55\% de participação da polpa cítrica peletizada na MS da dieta. A composição química corporal foi estimada a partir de equações desenvolvidas para a mesma raça, utilizando-se a composição química do corte da 9-10-11 costelas. A participação da polpa cítrica peletizada não afetou significativamente o peso corporal final (449 kg) e os ganhos diários de peso corporal $(1,50 \mathrm{~kg})$, de corpo vazio $(1,26 \mathrm{~kg})$ e de carcaça $(0,78 \mathrm{~kg})$. Não houve diferença entre tratamentos para as taxas diárias de deposição de água $(0,374 \mathrm{~kg})$, EE $(0,589 \mathrm{~kg})$, proteína $(0,253 \mathrm{~kg})$, minerais $(0,040 \mathrm{~kg})$ e energia $(6,934 \mathrm{Mcal})$ e, conseqüentemente, a composição química corporal final foi similar entre os animais recebendo diferentes níveis de polpa cítrica na dieta. A substituição do milho em grão por polpa cítrica peletizada, até $55 \%$ da $\mathrm{MS}$, em dietas para tourinhos em terminação recebendo altos níveis de concentrado, não altera os ganhos de peso, as taxas de deposição e a composição química corporal desses animais.
\end{abstract}

Palavras-chave: bovinos de corte, composição do ganho, constituintes corporais, corpo vazio

\section{Live weight gains, deposition rates and body chemical composition of Santa Gertrudis young bulls, fed high concentrate diets with increasing levels of dehydrated citrus pulp pellets}

\begin{abstract}
The objective of this trial was to evaluate the effects of replacing corn grain with dehydrated citrus pulp pellets on body weight gains, deposition rates of nutrients and body chemical composition of Santa Gertrudis young bulls Twenty-eight animals averaging nine months of age and initial body weight of $277 \mathrm{~kg}$ were kept in individual pens during 92 days after 21 days of adaptation. Animals were fed a diet containing 20\% (DM basis) of 40\%-grain corn silage. The following dietary levels of dehydrated citrus pulp pellets ( $\%$ dry matter) were fed: $0,25,40$ or 55\%. Body chemical composition was estimated from equations developed for Santa Gertrudis using the chemical composition of 9-10-11 th ribs cut. Increasing levels of citrus pulp had no significant effects on final body weight $(449 \mathrm{~kg})$ and on daily gains of body weight $(1.50 \mathrm{~kg})$, empty body $(1.26 \mathrm{~kg})$ and carcass $(0.78 \mathrm{~kg})$. There were no significant differences among treatments on daily rates of deposition of water $(0.374 \mathrm{~kg})$, EE $(0.589 \mathrm{~kg})$, protein $(0.253 \mathrm{~kg})$, ash $(0.040 \mathrm{~kg})$ and energy $(6.934 \mathrm{Mcal})$. Therefore, final body chemica composition was similar across diets. Dehydrated citrus pulp pellets can replace corn grain, up to $55 \%$ of diet DM, with no detrimental effects on daily gains, deposition rates and body chemical composition of finishing Santa Gertrudis young bulls fed high concentrate diets.
\end{abstract}

Key Words: beef cattle, body components, empty body, gain composition

\section{Introdução}

A composição corporal muda ao longo do crescimento do animal, como conseqüência de fatores como idade, sexo, raça e nível nutricional (ARC, 1980), e a medição dessa mudança é importante na determinação das exigências de energia, proteína e minerais para ganho de peso. A raça e o sexo afetam mais a composição do ganho de peso que a taxa 
diária de ganho de peso. Segundo Reid et al. (1980), raças de maturidade precoce têm mais gordura e menos proteína para determinado peso que as de maturidade tardia.

O crescimento animal consiste na deposição de proteína, gordura e minerais (Owens et al., 1995). Quando o animal atinge o peso adulto (maturidade fisiológica), a deposição líquida de proteína é praticamente nula (Owens et al., 1993). O animal passa, então, a depositar praticamente só gordura (NRC, 1996). A taxa de deposição de proteína depende da idade e do peso adulto e aumenta à medida que a taxa de ganho de peso vazio se eleva. Em animais de raças européias, a deposição de gordura atinge níveis máximos (em torno de $550 \mathrm{~g} / \mathrm{dia}$ ) quando os animais têm acesso a rações contendo elevado teor de concentrado e apresenta ganho superior a $1,3 \mathrm{~kg} /$ dia (Owens et al., 1995). Entretanto, poucos estudos foram devolvidos com a finalidade de avaliar esses parâmetros em animais zebuínos e mestiços.

Dietas à base de milho em grão e com elevada proporção de concentrado proporcionam aproximadamente $40 \%$ a mais de ganho de peso e $50 \%$ a mais de ganho de peso em carcaça em comparação àquelas com baixo nível de concentrado (Leme et al., 2000). Segundo Fox et al. (1992), dietas com alta proporção de concentrado, quando o nível de energia consumida é alto, promovem aumento na taxa de ganho e na concentração de gordura nos tecidos depositados.

A determinação indireta da composição química corporal a partir da composição do corte da 9-10-11 $\underline{\text { a }}$ costelas foi inicialmente proposta por Hankins \& Howe (1946). No Brasil, Lanna et al. (1995) e Alleoni et al. (1997) desenvolveram equações para estudos em bovinos da raça Nelore inteiros e castrados, respectivamente. Equações específicas para estimativa da composição química corporal de machos inteiros Santa Gertrudes a partir da composição química do corte da 9-10-11 $\underline{a}$ costelas foram desenvolvidas por Henrique et al. (2003a).

A polpa cítrica peletizada, um subproduto da produção de suco de laranja, pode ser utilizada na alimentação de ruminantes, principalmente como componente energético da dieta, e tem sido disponibilizada no mercado interno nos últimos anos a um preço razoável. Henrique et al. (1998) constataram que a polpa cítrica em rações com baixa proporção de concentrado apresentou valor nutritivo semelhante ao do milho, mas, em dietas com alta proporção de concentrado, a substituição do milho pela polpa cítrica determinou reduções drásticas no ganho de peso, em razão do elevado nível de cálcio nesse subproduto, afetando a ingestão de alimentos. Leme et al. (2000) afirmaram que esse tipo de dieta resultou também em menores ganhos de carcaça.
O objetivo neste trabalho foi avaliar os efeitos de níveis de substituição do milho em grão pela polpa cítrica peletizada em dietas com elevada proporção de concentrado sobre os ganhos de peso vazio e de carcaça, as taxas de deposição dos componentes corporais e a composição química corporal de tourinhos Santa Gertrudes em confinamento.

\section{Material e Métodos}

O experimento foi conduzido no Instituto de Zootecnia de São José do Rio Preto, SP, utilizando-se animais provenientes do rebanho do próprio Instituto, mantidos em confinamento, após desmama, em baias coletivas.

Foram selecionados 28 tourinhos Santa Gertrudes com idade média de nove meses e $277 \mathrm{~kg}$ de peso inicial, que permaneceram confinados em baias individuais, parcialmente cimentadas e cobertas. No início do experimento, os animais foram distribuídos, de acordo com o peso, em blocos alocados aleatoriamente na instalação, onde foram mantidos em confinamento durante 92 dias, após o período de adaptação (21 dias).

Outros seis tourinhos (animais-referência), nas mesmas condições, foram abatidos no início do período experimental, após jejum completo de 18 horas, para determinação da composição química corporal, feita diretamente, por meio da moagem de todos os tecidos do corpo.

O volumoso básico utilizado foi silagem de milho com $40 \%$ de grãos, sendo essa proporção determinada no momento da ensilagem. Foram avaliadas quatro dietas com diferentes participações $(0,25,40$ e $55 \%$ daMS $)$ de polpa cítrica peletizada em substituição ao milho em grão. As dietas foram ajustadas pelo modelo Cornell Net Carbohydrate and Protein System CNCPS (Sniffen et al., 1992) para atender às exigências de proteína degradável no rúmen e proteína metabolizável para a categoria animal utilizada (Tabela 1), além das exigências de aminoácidos e peptídeos das bactérias do rúmen. Os valores estimados de alguns nutrientes, calculados a partir da composição dos ingredientes, segundo o NRC (1996), são descritos na Tabela 1.

Os tratamentos consistiram da substituição de $0,38,62$ e $86 \%$ do milho, respectivamente, para os tratamentos com $0,25,40$ e $55 \%$ de polpa cítrica na MS da dieta.

Os alimentos foram fornecidos em forma de ração completa, em duas refeições diárias, e os animais tiveram livre acesso à água. A quantidade de volumoso foi corrigida diariamente e a de concentrado, semanalmente, permitindo-se aproximadamente $10 \%$ de sobras. Os cochos foram limpos duas vezes por semana, desprezando-se as sobras. Semanalmente, foram determinados os teores de MS das sobras 
Tabela 1 - Composição das dietas experimentais (porcentagem da matéria seca)

Table 1 - Composition of the experimental diets (percent of dry matter)

Ingrediente

Ingredient
Dieta experimental - Porcentagem de polpa cítrica Experimental diet - Percent of citrus pulp

\begin{tabular}{rrrr}
\multicolumn{4}{c}{$\begin{array}{c}\text { Dieta experimental } \\
\text { Experimental diet }- \text { Percent of citrus pulp } \\
\text { Ex cítrica }\end{array}$} \\
\hline \multicolumn{1}{c}{25} & 40 & \multicolumn{1}{c}{55} \\
\hline 20,00 & 20,00 & 20,00 & 20,00 \\
0,00 & 25,00 & 40,00 & 55,00 \\
67,40 & 41,45 & 25,65 & 9,35 \\
10,20 & 12,20 & 13,00 & 14,10 \\
0,00 & 0,20 & 0,30 & 0,50 \\
0,30 & 0,30 & 0,30 & 0,30 \\
0,02 & 0,02 & 0,02 & 0,02 \\
0,03 & 0,03 & 0,03 & 0,03 \\
1,10 & 0,00 & 0,00 & 0,00 \\
0,70 & 0,70 & 0,70 & 0,70 \\
0,25 & 0,10 & 0,00 & 0,00 \\
\hline
\end{tabular}

Silagem de milho (Corn silage)

Polpa cítrica (Citrus pulp)

Milho em grão (Corn grain)

Farelo de soja (Soybean meal)

Fosfato bicálcico (Dicalcium phosphate)

Uréia (Urea)

Monensina sódica (Sodium monensin)

Sulfato de amônio (Ammonium sulphate)

Calcário calcítico (Limestone)

Sal mineral* (Mineral salt)

Cloreto de potássio (Potassium chloride)

Valor estimado

Estimated value

Nutrientes digestíveis totais, \% (Total digestible nutrients, \%)

Energia metabolizável, Mcal $/ \mathrm{kg}$ (Metabolizable energy, Mcal/kg)

Proteína bruta, \% da MS (Crude protein, \% of DM)

82,73

2,99

13,60

0,43

81,57
2,95
13,70
0,56

80,17

2,90

13,60

0,86

78,94

2,85

13,60

1,18

* Níveis de garantia por kg (Guarantee levels per $\mathrm{kg}$ ): $\mathrm{Ca}=271 \mathrm{~g}, \mathrm{P}=29 \mathrm{~g}, \mathrm{Mg}=20 \mathrm{~g}, \mathrm{~S}=31 \mathrm{~g}, \mathrm{Na}=62 \mathrm{~g}, \mathrm{Zn}=1.350 \mathrm{mg}, \mathrm{Cu}=340 \mathrm{mg}, \mathrm{Fe}=1.064 \mathrm{mg}$ $\mathrm{Mn}=940 \mathrm{mg}, \mathrm{Co}=10 \mathrm{mg}, \mathrm{I}=25 \mathrm{mg}$ e Se $=10 \mathrm{mg}$;

1 Estimativa a partir da composição dos ingredientes (NRC, 1996) (Estimated from the ingredient composition [NRC, 1996]).

e dos alimentos oferecidos, para o ajuste da relação volumoso:concentrado.

A composição em minerais foi determinada conforme metodologia da AOAC (1995) e a de FDN e FDA, de acordo com Van Soest et al. (1991).

Os animais foram pesados no início e ao final do período experimental, após jejum completo de 18 horas. Ao final do período experimental, foram abatidos, retirando-se o corte da 9-10-11 a costelas, após resfriamento por 24 horas, segundo metodologia de Hankins \& Howe (1946).

A determinação da porcentagem de água do corte da 9-10-11 ${ }^{\mathrm{a}}$ costelas foi realizada no Instituto de Zootecnia, em Nova Odessa, SP, após liofilização ( 80 horas) e moagem em equipamento com motor de 15 HP (Alleoni et al., 1997).

A composição química corporal foi estimada utilizando-se as seguintes equações, desenvolvidas por Henrique et al. (2003a) para tourinhos Santa Gertrudes:

1) $\%$ água corpo vazio $=1,1221 \%$ água costela $-6,4839$ $\left(\mathrm{R}^{2}=0,95\right)$

2) $\%$ EE corpo vazio $=-1,0192 \%$ água corpo vazio + $76,8675\left(\mathrm{R}^{2}=0,94\right)$;

sendo EE o extrato etéreo e considerando-se o corpo vazio o peso do corpo do animal menos o conteúdo do trato gastrintestinal, da bexiga e da bílis.

Segundo esses autores, os valores de proteína e minerais naMS desengordurada foram, respectivamente, 82,52 e 17,48\%. Os teores de energia da gordura e da proteína usados foram 9,343 e 5,641 Mcal $/ \mathrm{kg}$, respectivamente (Boin et al., 1994).
O peso inicial da carcaça quente foi calculado a partir do rendimento de carcaça dos animais-referência, ao passo que a composição química corporal inicial, pela composição química corporal desses animais. O peso vazio dos animais foi estimado por meio da regressão entre peso do corpo vazio e peso da carcaça, desenvolvida por Henrique et al. (2003a), obtendo-se a seguinte equação:

$$
\begin{gathered}
\text { peso vazio }=1,6093 \text { peso carcaça quente }+0,6784 \\
\left(\mathrm{R}^{2}=0,99\right)
\end{gathered}
$$

Foram obtidos, então, os pesos corporais iniciais e finais, os pesos corporais vazios iniciais e finais, os pesos de carcaça iniciais e finais, os ganhos de peso corporais, do corpo vazio e da carcaça, a composição química corporal inicial (porcentagens de água, EE, proteína e minerais), a composição química final, as taxas de deposição dos componentes corporais e a composição do ganho.

Todas as variáveis foram analisadas (SAS, 1996) quanto à normalidade de distribuição pelo teste de Shapiro-Wilk e quanto à homogeneidade da variância, pelo teste de Bartlett, considerando-se o nível de 5\% de significância.

Após essas análises preliminares, tendo sido satisfatórias, os resultados foram analisados estatisticamente por regressão polinomial, considerando-se blocos ao acaso, com sete repetições e quatro tratamentos $(0,25$, 40 e $55 \%$ de polpa cítrica peletizada na MS da dieta). O valor do coeficiente de determinação foi calculado a partir da 
soma de quadrados da regressão considerada significativa dividida pela soma de quadrados de tratamento.

\section{Resultados e Discussão}

A polpa cítrica peletizada utilizada no experimento apresentou $85,46 \%$ de MS e a seguinte composição, em porcentagem da MS: 5,99 de PB; 1,48 de EE; 4,67 de MM; 1,22 de Ca; e 0,09 de P.

A composição químico-bromatológica do volumoso e dos concentrados utilizados está apresentada na Tabela 2 .

Os resultados de desempenho no confinamento e as características de carcaça foram publicados em outro trabalho (Henrique et al., 2004).

Os pesos corporais inicial e final, os pesos de corpo vazio e de carcaça (inicial e final), os ganhos de peso e os ganhos de peso de corpo vazio e de carcaça são descritos na Tabela 3. Ressalta-se que os pesos iniciais foram calculados a partir do rendimento de carcaça dos animaisreferência $(54,41 \%)$.

Os pesos corporais iniciais e os pesos de corpo vazio e de carcaça não foram alterados pelos tratamentos $(\mathrm{P}>0,05)$. $O$ peso final dos animais e o rendimento de carcaça não foram influenciados pela porcentagem de polpa cítrica na dieta $(\mathrm{P}>0,05)$, mas os pesos finais de carcaça e de corpo vazio variaram significativamente conforme os tratamentos $(\mathrm{P}=0,0244)$, tendo sido maiores nos níveis mais elevados de participação da polpa cítrica. As equações obtidas são apresentadas na Tabela 3.

Tabela 2 - Composição químico-bromatológica da silagem de milho e dos concentrados utilizados

Table 2 - Chemical composition of corn silage and concentrates

\begin{tabular}{|c|c|c|c|c|c|}
\hline \multirow[t]{2}{*}{$\begin{array}{l}\text { Componente } \\
\text { Item }\end{array}$} & \multirow[t]{2}{*}{$\begin{array}{l}\text { ilagem milho } \\
\text { Corn silage }\end{array}$} & \multicolumn{4}{|c|}{$\begin{array}{l}\text { Porcentagem de polpa cítrica } \\
\text { Percent of citrus pulp }\end{array}$} \\
\hline & & 0 & 25 & 40 & 55 \\
\hline $\begin{array}{l}\text { Matéria seca, \% } \\
\text { Dry matter. \% }\end{array}$ & 35,02 & 87,87 & 86,65 & 86,78 & 85,42 \\
\hline $\begin{array}{l}\text { Proteína bruta }{ }^{1} \\
\text { Crude protein }\end{array}$ & 8,59 & 15,42 & 15,13 & 14,96 & 15,22 \\
\hline $\begin{array}{l}\text { Extrato etéreo }{ }^{1} \\
\text { Ether extract }\end{array}$ & 2,78 & 3,15 & 2,98 & 2,86 & 2,66 \\
\hline $\begin{array}{l}\text { Matéria mineral }{ }^{1} \\
\text { Ash }\end{array}$ & 3,15 & 4,02 & 4,35 & 4,92 & 6,50 \\
\hline $\begin{array}{l}\text { Matéria orgânica }{ }^{1} \\
\text { Organic matter }\end{array}$ & 96,85 & 95,98 & 95,65 & 95,08 & 93,50 \\
\hline $\begin{array}{l}\text { Fibra detergente neutro }{ }^{1} \\
\text { Neutral detergent fiber }\end{array}$ & $0^{1} 53,67$ & 38,80 & 35,66 & 32,45 & 30,28 \\
\hline $\begin{array}{l}\text { Fibra detergente ácido }{ }^{1} \\
\text { Acid detergent fiber }\end{array}$ & 128,46 & 4,32 & 8,89 & 11,43 & 14,72 \\
\hline $\begin{array}{l}\text { Hemicelulose }^{1} \\
\text { Hemicellulose }\end{array}$ & 25,21 & 34,48 & 26,77 & 21,02 & 15,56 \\
\hline $\begin{array}{l}\text { Lignina }^{1} \\
\text { Lignin }^{-1}\end{array}$ & 7,64 & 1,76 & 1,98 & 2,74 & 3,05 \\
\hline
\end{tabular}

${ }^{1}$ Porcentagem da matéria seca (Percentage of dry matter).
A substituição do milho em grão pela polpa cítrica peletizada como fonte de energia não alterou o ganho de peso dos animais $(\mathrm{P}>0,05)$ ou os ganhos de peso vazio e de carcaça.

Apesar de não ter sido detectada diferença estatística para os ganhos, diferenças numéricas foram observadas entre os tratamentos, as quais, aliadas às diferenças no peso inicial dos animais (embora também não significativas), podem justificar as diferenças estatisticamente significativas encontradas entre tratamentos para o peso final do corpo vazio e da carcaça.

Leme et al. (2000) demonstraram a necessidade da avaliação do ganho de peso de carcaça em relação ao ganho de peso em jejum, principalmente pelo impacto econômico, que muitas vezes é ignorado. Os autores apontaram que essa avaliação é especialmente importante para formulação de dietas com maiores porcentagens de volumosos, em que o ganho de peso é composto de maior proporção de enchimento do trato gastrintestinal. As relações percentuais entre o ganho de peso de carcaça e o ganho de peso corporal obtidos para os tratamentos avaliados são ilustradas na Figura 1.

A composição do corte da 9-10-11 $\stackrel{a}{\text { - }}$ costelas e a composição corporal obtida, utilizando-se as equações obtidas por Henrique et al. (2003a), encontram-se na Tabela 4. Os resultados da composição corporal dos animais-referência foram obtidos de forma direta, por meio da moagem de todos os tecidos do animal.

Os valores obtidos para a porcentagem de água no corpo vazio foram inferiores aos obtidos por Leme et al. (2000), em média $60 \%$, que utilizaram animais da mesma categoria e raça, alimentados com dietas com mesma porcentagem de concentrado. Esses autores, no entanto,

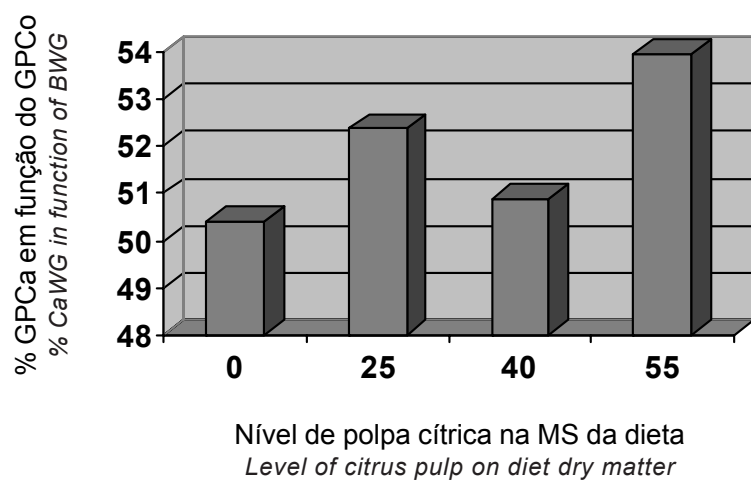

Figura 1 - Relação percentual entre ganho de peso de carcaça (GPCa) e ganho de peso corporal (GPCo), de acordo com o nível de polpa cítrica na MS da dieta.

Figure 1 - Relationship between carcass (CaWG) and body weight (BWG) gains in function of the level of citrus pulp on diet dry matter. 
Tabela 3 - Pesos iniciais e finais e ganhos de peso corporal, de carcaça e de corpo vazio Table 3 - Initial and final body, carcass and empty body weights and weight gains

\begin{tabular}{|c|c|c|c|c|c|}
\hline \multirow[t]{2}{*}{$\begin{array}{l}\text { Parâmetro } \\
\text { Item }\end{array}$} & \multicolumn{4}{|c|}{$\begin{array}{c}\text { Porcentagem de polpa cítrica } \\
\text { Percent of citrus pulp }\end{array}$} & \multirow[t]{2}{*}{$\mathrm{CV}(\%)^{1}$} \\
\hline & 0 & 25 & 40 & 55 & \\
\hline Peso carcaça inicial, $\mathrm{kg}$ (Initial carcass weight, $\mathrm{kg}$ ) & 166,08 & 168,05 & 171,19 & 171,87 & 3,73 \\
\hline Peso corpo vazio inicial, $\mathrm{kg}$ (Initial empty body weight, $\mathrm{kg}$ ) & 267,95 & 271,13 & 276,18 & 277,26 & 3,72 \\
\hline Peso corporal final, $\mathrm{kg}$ (Final body weight, $\mathrm{kg}$ ) & 439,71 & 452,71 & 450,43 & 454,86 & 3,64 \\
\hline Rendimento carcaça, \% (Carcass dressing, \%) & 53,17 & 53,69 & 53,25 & 54,33 & 2,66 \\
\hline Ganho de peso corporal, $\mathrm{kg} / \mathrm{dia}$ (Body weight gain, $\mathrm{kg} /$ day) & 1,462 & 1,564 & 1,476 & 1,511 & 8,62 \\
\hline Ganho de peso carcaça, $\mathrm{kg} /$ dia (Carcass weight gain, $\mathrm{kg} /$ day) & 0,737 & 0,819 & 0,751 & 0,815 & 13,44 \\
\hline Ganho peso corpo vazio, $\mathrm{kg} / \mathrm{dia}$ (Empty body weight gain, $\mathrm{kg} /$ day) & 1,186 & 1,319 & 1,209 & 1,312 & 13,45 \\
\hline
\end{tabular}

${ }^{1} \mathrm{CV}$ - Coeficiente de variação (Coefficient of variation).

${ }^{2} \hat{Y}=234,8993+0,2069 \times\left(R^{2}=0,91\right)$.

${ }^{3} \hat{Y}=378,7019+0,3330 \times\left(R^{2}=0,77\right)$.

Tabela 4 - Composição química do corte da 9-10-11a costelas e do corpo vazio dos animais-referência e dos animais experimentais Table 4 - Chemical composition of the 9-10-11 th ribs and of the empty body of the experimental and reference animals

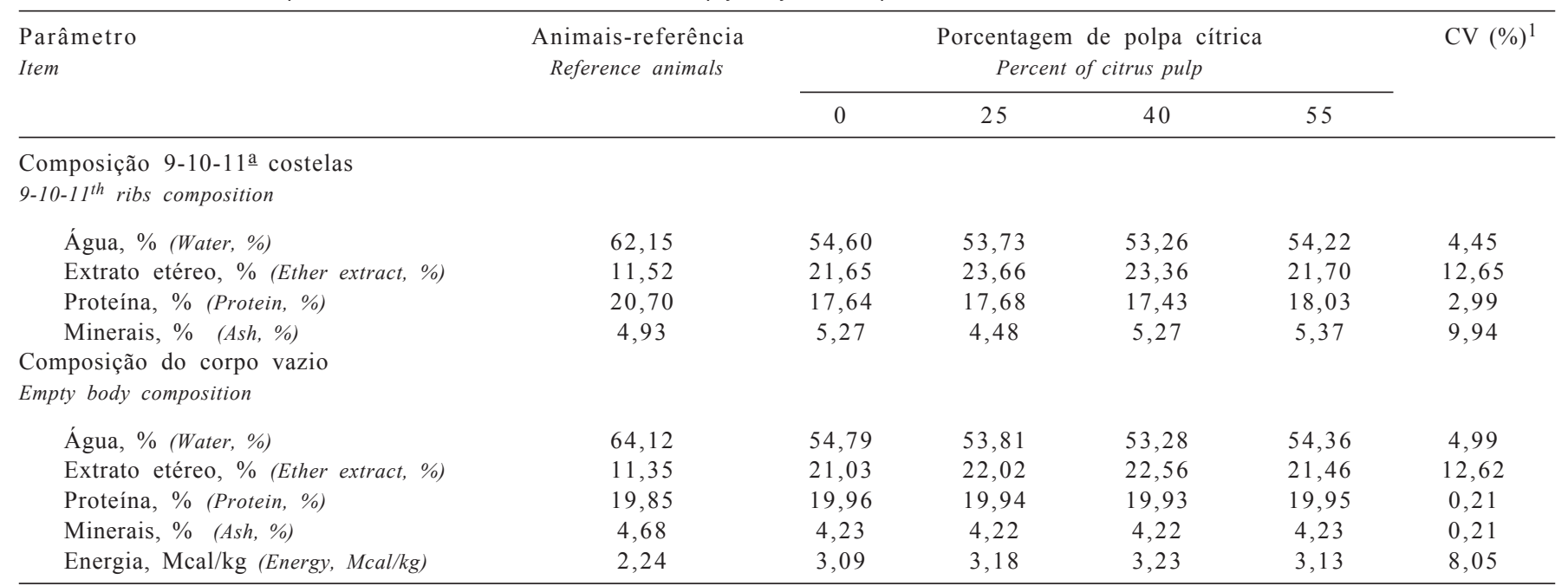

${ }^{1} \mathrm{CV}$ - Coeficiente de variação (Coefficient of variation).

encontraram teores médios de EE de $16 \%$, inferiores aos descritos na Tabela 4, e valores semelhantes de proteína e minerais. Conseqüentemente, a concentração de energia do corpo vazio foi inferior, aproximadamente $2,6 \%$. Provavelmente essas diferenças foram decorrentes do menor peso de abate dos animais no trabalho de Leme et al. (2000), que foi de $406 \mathrm{~kg}$ para o tratamento com $80 \%$ de concentrado e milho em grão como componente energético.

Bulle et al. (2002) não notaram diferenças no teor de EE do corpo vazio de tourinhos de diferentes tipos genéticos paternos (Britânicos e Continentais), alimentados com diferentes níveis de volumoso $(9,15$ e $21 \%$ de bagaço in natura na MS da dieta), sendo que a média foi de $18 \%$ aos $400 \mathrm{~kg}$ de peso de corpo vazio final. Lanna et al. (1997), por sua vez, encontraram teores de EE no corpo vazio de 19, 16 e $18 \%$, respectivamente, para animais Nelore, Nelore $\mathrm{x}$
Marchigiana e mestiços leiteiros. Esses teores foram baixos considerando-se que o peso de abate foi de $500 \mathrm{~kg}$, contudo, os animais eram inteiros e estavam em ganho compensatório. Os teores de EE no corpo vazio dos animais deste trabalho foram um pouco acima (22\%), observando-se que esses animais também eram inteiros. Berndt et al. (2002), em estudo com animais Santa Gertrudes, avaliaram dietas com alto teor de concentrado e silagem de grão de milho úmido e observaram valores semelhantes desse nutriente, sendo que os animais foram abatidos com peso de corpo vazio de $407 \mathrm{~kg}$. Sabe-se que a deposição de gordura tende a elevar-se com o aumento do peso corporal, comparando-se animais de mesmo grupo genético e tamanho corporal (Fox et al., 1992).

Backes et al. (2002) estimaram a composição do corpo vazio de machos castrados Santa Gertrudes com três anos de idade e $400 \mathrm{~kg}$ de peso vazio em 15,8 e $20,6 \%$ e 2,711 
$\mathrm{Mcal} / \mathrm{kg}$, respectivamente, para os teores de EE, proteína e energia. Os animais deste experimento apresentaram maior proporção de EE e, conseqüentemente, de energia, embora fossem animais inteiros e mais jovens, situação em que se esperaria menor porcentagem de EE. É provável que o menor teor de EE obtido por Backes et al. (2002) seja decorrente da dieta utilizada, que apresentava $70 \%$ de volumoso em sua composição.

A composição final do corpo vazio (em porcentagem de água, proteína e minerais) dos tourinhos Santa Gertrudes avaliados por Berndt et al. (2002) foi semelhante à obtida neste trabalho, ressaltando-se que esses autores trabalharam também com animais jovens, inteiros e com $80 \%$ de concentrado na MS da dieta.

As quantidades de água, EE, proteína e minerais no corpo vazio no início e no final do experimento encontram-se na Tabela 5.

No corpo vazio final, apenas as quantidades de proteína e minerais foram influenciadas pela participação da polpa cítrica, ambas com aumento linear de acordo com o aumento da proporção de polpa $(\mathrm{P}=0,0232)$. Esse aumento da quantidade de proteína depositada, segundo Henrique et al. (2003b), pode ser resultado da melhora do balanço de nitrogênio e da digestibilidade da PB com o aumento da participação da polpa cítrica na MS da dieta, que favorece os padrões de fermentação ruminal e do aproveitamento dos nutrientes, como conseqüência da efetividade da fibra desse ingrediente.

A quantidade de EE no corpo vazio final foi maior que a obtida por Leme et al. (2000), que registraram apenas $57 \mathrm{~kg}$ dessa fração em animais alimentados com dietas com $80 \%$ de concentrado e milho em grão como componente energético. Isso indica que os animais deste experimento apresentavam melhor acabamento, mesmo porque foram abatidos com pesos mais elevados.

Constam na Tabela 6 as taxas de deposição das frações e a composição percentual do ganho de peso de corpo vazio.

As taxas de deposição de água, EE, proteína, minerais e energia não foram alteradas significativamente $(\mathrm{P}>0,05)$ pela porcentagem de polpa cítrica na dieta.

Os animais apresentavam, no início e no final do período experimental, pesos mais elevados que aqueles utilizados no trabalho de Leme et al. (2000), o que pode ter determinado taxas de deposição, principalmente de água e energia, diferentes. Esses autores obtiveram taxas de deposição de água e EE de 0,606 e 0,305 kg/dia, respectivamente, observando-se, portanto, uma inversão: a taxa de deposição de água foi inferior e a de deposição de EE superior à deste trabalho.

A composição percentual do ganho de peso de corpo vazio em água, EE e proteína também não foi significativamente influenciada $(\mathrm{P}>0,05)$ pela porcentagem de polpa cítrica na dieta. As diferenças nos pesos dos animais também justificam a composição do ganho diferente entre os deste estudo (Tabela 6) e os reportados por Leme et al. (2000), que obtiveram 51,44 e $25,88 \%$ de água e EE, respectivamente, para os animais do tratamento com $80 \%$ de concentrado e milho em grão.

Tabela 5 - Composição química do corpo vazio dos animais no início e no final do experimento Table 5 - Empty body chemical composition in the beginning and end of the experiment

\begin{tabular}{|c|c|c|c|c|c|}
\hline \multirow[t]{2}{*}{$\begin{array}{l}\text { Parâmetro } \\
\text { Item }\end{array}$} & \multicolumn{4}{|c|}{$\begin{array}{c}\text { Porcentagem de polpa cítrica } \\
\text { Percent of citrus pulp }\end{array}$} & \multirow[t]{2}{*}{$\mathrm{CV}(\%)^{1}$} \\
\hline & 0 & 25 & 40 & 55 & \\
\hline $\begin{array}{l}\text { Água, } \mathrm{kg} \text { (Water, kg) } \\
\text { Extrato etéreo, kg (Ether extract, kg) } \\
\text { Proteína, kg (Protein, kg) } \\
\text { Minerais, } \mathrm{kg} \text { (Ash, kg) } \\
\text { Energia, Mcal (Energy, Mcal) }\end{array}$ & $\begin{array}{c}171,810 \\
30,412 \\
53,188 \\
12,540 \\
584,178\end{array}$ & $\begin{array}{c}173,846 \\
30,773 \\
53,818 \\
12,689 \\
591,100\end{array}$ & $\begin{array}{l}177,084 \\
31,346 \\
54,821 \\
12,925 \\
602,109\end{array}$ & $\begin{array}{l}177,782 \\
31,470 \\
55,037 \\
12,976 \\
604,483\end{array}$ & $\begin{array}{l}3,72 \\
3,72 \\
3,72 \\
3,72 \\
3,72\end{array}$ \\
\hline \multicolumn{6}{|l|}{$\begin{array}{l}\text { Composição final } \\
\text { Final composition }\end{array}$} \\
\hline $\begin{array}{l}\text { Água, } \mathrm{kg} \text { (Water, } \mathrm{kg} \text { ) } \\
\text { Extrato etéreo, kg (Ether extract, kg) } \\
\text { Proteína }^{2}, \mathrm{~kg} \text { (Protein, } \mathrm{kg} \text { ) } \\
\text { Minerais }^{3}, \mathrm{~kg} \text { (Ash, kg) } \\
\text { Energia, Mcal (Energy, Mcal) }\end{array}$ & $\begin{array}{c}205,623 \\
80,238 \\
75,228 \\
15,935 \\
1174,027\end{array}$ & $\begin{array}{c}210,514 \\
87,094 \\
78,245 \\
16,575 \\
1255,105\end{array}$ & $\begin{array}{c}206,145 \\
87,659 \\
77,211 \\
16,355 \\
1254,543\end{array}$ & $\begin{array}{c}215,897 \\
85,848 \\
79,384 \\
16,816 \\
1249,888\end{array}$ & $\begin{array}{c}4,99 \\
13,97 \\
3,68 \\
3,68 \\
9,78\end{array}$ \\
\hline
\end{tabular}

${ }^{1} \mathrm{CV}$ - Coeficiente de variação (Coefficient of variation).

$2 \hat{Y}=75,5416+0,0658 \times\left(R^{2}=0,77\right)$.

${ }^{3} \hat{Y}=16,0019+0,0139 \times\left(R^{2}=0,76\right)$. 
Tabela 6 - Taxa de deposição dos componentes químicos corporais e composição percentual do ganho de peso vazio Table 6 - Body deposition rates of nutrients and empty weight gain composition

\begin{tabular}{|c|c|c|c|c|c|}
\hline \multirow[t]{2}{*}{$\begin{array}{l}\text { Parâmetro } \\
\text { Item }\end{array}$} & \multicolumn{4}{|c|}{$\begin{array}{c}\text { Porcentagem de polpa cítrica } \\
\text { Percent of citrus pulp }\end{array}$} & \multirow[t]{2}{*}{$\mathrm{CV}(\%)^{1}$} \\
\hline & 0 & 25 & 40 & 55 & \\
\hline \multirow{2}{*}{\multicolumn{6}{|c|}{$\begin{array}{l}\text { Taxas de deposição } \\
\text { Deposition rates }\end{array}$}} \\
\hline & & & & & \\
\hline Água, $\mathrm{kg} / \mathrm{dia}$ (Water, $\mathrm{kg} /$ day) & 0,367 & 0,398 & 0,316 & 0,414 & 37,90 \\
\hline Extrato etéreo, $\mathrm{kg} /$ dia (Ether extract, $\mathrm{kg} /$ day) & 0,542 & 0,612 & 0,612 & 0,591 & 21,30 \\
\hline Proteína, kg/dia (Protein, kg/day) & 0,239 & 0,265 & 0,243 & 0,265 & 13,23 \\
\hline Minerais, $\mathrm{kg} / \mathrm{dia}($ Ash, $\mathrm{kg} /$ day $)$ & 0,037 & 0,042 & 0,037 & 0,042 & 18,85 \\
\hline Energia, Mcal/dia (Energy, Mcal/day) & 6,411 & 7,217 & 7,092 & 7,015 & 17,96 \\
\hline \multicolumn{6}{|l|}{$\begin{array}{l}\text { Composição do ganho de peso vazio } \\
\text { Empty weight gain composition }\end{array}$} \\
\hline Água, \% (Water, \%) & 31,610 & 29,823 & 26,184 & 31,163 & 32,60 \\
\hline Extrato etéreo, \% (Ether extract, \%) & 45,064 & 46,854 & 50,600 & 45,491 & 21,04 \\
\hline Proteína, \% (Protein, \%) & 20,223 & 20,146 & 20,146 & 20,172 & 0,75 \\
\hline Minerais, \% (Ash, \%) & 3,103 & 3,177 & 3,071 & 3,173 & 5,69 \\
\hline
\end{tabular}

${ }^{1} \mathrm{CV}$ - Coeficiente de variação (Coefficient of variation).

A porcentagem de lipídeo no ganho de corpo vazio encontrada por Bulle et al. (2002) foi de 28,5 aos $400 \mathrm{~kg}$ de peso vazio ao abate, muito inferior à encontrada na literatura para tourinhos descendentes de touros britânicos e continentais.

Considerando-se apenas o tratamento com silagem de milho e milho em grão, os resultados de composição do ganho de peso de corpo vazio obtidos por Berndt et al. (2002) foram 38\% em forma de água, 39\% como EE, 18\% como proteína e $4,5 \%$ como minerais. Neste experimento, houve menor deposição percentual de água e maior de EE. Berndt et al. (2002) trabalharam com animais muito semelhantes aos desse experimento e obtiveram coeficientes de variação similires para a composição do ganho em água e extrato etéreo.

Backes et al. (2002) determinaram valores de 46,6 e $19,4 \%$, respectivamente, para a composição do ganho de peso de corpo vazio em EE e proteína, valores muito próximos aos descritos na Tabela 6 .

Os resultados de composição corporal são importantes para integrar um banco de dados do crescimento de tourinhos mestiços Zebus para elaboração de recomendações de alimentação destes animais.

\section{Conclusões}

A polpa cítrica peletizada pode substituir o milho em grão, como componente energético, em até $55 \%$ da MS da dieta, na terminação de tourinhos mestiços recebendo dietas com teores elevados de concentrado, pois não alterou as taxas de deposição dos constituintes corporais e a compo- sição química corporal final. A polpa cítrica proporcionou, inclusive, melhora no peso final da carcaça e do corpo vazio.

\section{Literatura Citada}

ASSOCIATION OF OFFICIAL ANALYTICAL CHEMISTS AOAC. Official methods of analysis. 16.ed. Washington: 1995. v.1, p.1-30.

AGRICULTURAL RESEARCH COUNCIL - ARC. The nutrient requeriment of farm livestock. London: Commonwealth Agricultural Bureaux, 1980. 350p.

ALLEONI, G.F.; LEME, P.R.; BOIN, C. et al. Avaliação da composição química e física dos cortes da costela para estimar a composição química corporal de novilhos Nelore. Revista Brasileira de Zootecnia, v.26, n.2, p.382-390, 1997.

BACKES, A.A.; SANCHEZ, L.M.B.; GONÇALVES, M.B.F. et al. Composição corporal e exigências líquidas de energia e proteína para ganho de peso de novilhos Santa Gertrudes. Revista Brasileira de Zootecnia, v.31, n.6, p.2307-2313, 2002.

BERNDT, A.; HENRIQUE, W.; LANNA, D.P.D. et al. Milho úmido, bagaço de cana e silagem de milho em dietas de alto teor de concentrado. Composição corporal e taxas de deposição dos tecidos. Revista Brasileira de Zootecnia, v.31, n.5, p.2105-2112, 2002.

BOIN, C.; LANNA, D.P.D.; ALLEONI, G.F. et al. Tourinhos Nelore em crescimento e acabamento. In: REUNIÃO ANUAL DA SOCIEDADE BRASILEIRA DE ZOOTECNIA, 31., 1994, Maringá. Anais... Maringá: Sociedade Brasileira de Zootecnia, 1994. p.485.

BULLE, M.L.M.; RIBEIRO, F.G.; LEME, P.R. et al. Exigências líquidas de energia e proteína de tourinhos de dois grupos genéticos alimentados com dietas de alto teor de concentrado. Revista Brasileira de Zootecnia, v. 31, n.1, p.436-443, 2002 (supl.).

FOX, D.G.; SNIFFEN, C.J.; O'CONNOR, J.D. et al. A net carbohydrate and protein system for evaluating cattle diets. III. Cattle requirements and diet adequacy. Journal of Animal Science, v.70, n.11, p.3578-3596, 1992.

HANKINS, O.G.; HOWE, P.E. Estimation of the composition of beef carcasses and cuts. Washington: USDA, 1946. (Technical Bulletin, 926). 
HENRIQUE, W.; LEME, P.R.; LANNA, D.P.D. et al. Substituição de amido por pectina em dietas com diferentes níveis de concentrado. 1. Desempenho animal e características da carcaça. Revista Brasileira de Zootecnia, v.27, n.6, p.1206-1211, 1998.

HENRIQUE, W.; SAMPAIO, A.A.M.; LEME, P.R. et al. Estimativa da composição química corporal de tourinhos Santa Gertrudes a partir da composição química e física das costelas 9-10-11a . Revista Brasileira de Zootecnia, v.32, n.3, p.709-718, 2003 a.

HENRIQUE, W.; SAMPAIO, A.A.M.; LEME, P.R. et al. Digestibilidade e balanço de nitrogênio em ovinos alimentados à base de dietas com elevado teor de concentrado e níveis crescentes de polpa cítrica peletizada. Revista Brasileira de Zootecnia, v.32, n.6, p.2007-2015, 2003b (supl. 2).

HENRIQUE, W.; SAMPAIO, A.A.M.; LEME, P.R. et al. Desempenho e características da carcaça de tourinhos Santa Gertrudes confinados, recebendo dietas com alto concentrado e níveis crescentes de polpa cítrica peletizada. Revista Brasileira de Zootecnia, v.33, n.2, p.463-470, 2004.

LANNA, D.P.D.; BOIN, C.; ALLEONI, G.F. et al. Estimation of carcass and empty body composition of Zebu bulls using the composition of rib cuts. Sciencia Agricola, v.52, n.1, p.189-197, 1995.

LANNA, D.P.D.; LEME, P.R.; BOIN, C. et al. Ganho compensatório de bovinos de diferentes grupos genéticos: composição química e física corporal. In: REUNIÃO ANUAL DA SOCIEDADE BRASILEIRA DE ZOOTECNIA, 34., 1997, Juiz de Fora. Anais... Juiz de Fora: Sociedade Brasileira de Zootecnia, 1997, p.352-354.

LEME, P.R., LANNA, D.P.D., HENRIQUE, W. et al. Substituição do grão de milho por polpa de citros em dietas com diferentes níveis de concentrado. 2. Taxas de deposição e composição química corporal. Revista Brasileira de Zootecnia, v.29, n.3, p.834-839, 2000
NATIONAL RESEARCH COUNCIL - NRC. Nutrient requeriments of beef cattle. 7.ed. Washington, D.C: National Academy Press, 1996. 212p.

OWENS, F.N., DUBESKI, P., HANSON, C.F. Factors that alter the growth and development of ruminants. Journal of Animal Science, v.71, n.10, p.3138-3150, 1993.

OWENS, F.N., GILL, D.R., SECRIST, D.S. Review of some aspects of growth and development of feedlot cattle. Journal of Animal Science, v.73, n.10, p.3152-3172, 1995.

REID, J.T., WHITE, D.O., ANRIQUE, R. et al. Nutritional energetics of livestock: some present boundaries of knowledge and future research needs. Journal of Animal Science, v. 51 , n.6, p.1393, 1980.

SNIFFEN, C.J.; O'CONNOR, J.D.; Van SOEST, P.J. et al. A net carbohydrate and protein system for evaluating cattle diets. II. Carbohydrate and protein availability. Journal of Animal Science, v.70, n.11, p.3562-3577, 1992.

STATISTICAL ANALYSES SYSTEM - SAS. User's guide: statistic. 6.ed. Cary: 1996. 956p.

Van SOEST, P.J.; ROBERTSON, J.B.; LEWIS, B.A. Methods of dietary fiber, neutral detergent fiber, and nonstarch polysaccharides in relation to animal nutrition. Journal of Dairy Science, v.74, n.10, p.3583-3597, 1991 . 